plete skeletons and 1380 crania, irrespective of the Barnard Davis collection consisting of 24 skeletons and 1539 crania, which had been acquired in 1880 .

Shortly afterwards Macalister introduced anthropological work in his lectures at Cambridge. In I884 Galton instituted an anthropometric laboratory at the Health Exhibition, in which 10,000 individuals were measured, and afterwards installed the laboratory at South Kensington, where it continued. to exist for some years. A similar laboratory was established in Cambridge, and another in Dublin in I89I. In these activities the institute was interested either directly or through its fellows. In $\mathrm{I} 884$ it organised a conference in connection with the Indian and Colonial Exhibition, at which a large number of papers dealing with the native races of the Empire was read. As a direct outcome of the conference a movement was set on foot which led to the foundation of the Imperial Institute as a memorial of the jubilee of Queen Victoria in 1887 . The institute also took an active part in fostering the many movements with which Galton was connected, including the study of the physical and mental characteristics of our own population, the use of statistical methods in anthropology, and the introduction into this country of the system of identifying criminals both by anthropometric measurements and by the classification of finger-prints. In 1894 the position of Adviser to the Home Office on Criminal Identification was established, and continued to be held by a fellow of the institute for some years.

The second period comes to an end in 1898 . The enthusiasm which characterised the 'eighties and the early 'nineties had begun to wane, but with the intro- duction of new blood the institute made a vigorous step in a forward direction. The Journal was enlarged, the illustrations in particular being increased in number and improved in quality, and the monthly periodical Man was instituted, the first number being published in January, Igor. A broader view was taken of the institute's functions, and it entered upon a period of activity which was continued without interruption until the outbreak of war in IgI4.

The institute now began to urge with insistence the practical bearing of anthropology and anthropological data on administrative and legislative problems. The native question in South Africa, physical deterioration, anthropometrics in schools and the medical inspection of school-children, and the necessity for a knowledge of native customs and modes of thought in the government of backward races and as an essential part in the education of administrators of our Dependencies are some only of the numerous questions in connection with which the institute has urged its views upon the public and the Government. These activities were necessarily interrupted by the war. Setting aside this gap of six years, the last period still stands too close for us to gauge the direction of the institute's future development. Though the work of collecting material still goes on apace, and will continue so to do for some time, it may be permissible to hazard a guess that the future line of development must lie in the direction of the comparison and coordination of facts in order that these mav be presented as an organised body of knowledge, and thus made available for the educationist, the administrator, and the legislator.

E. N. F.

\title{
Publications of the U.S. National Research Council.
}

By J. W. Williamson.

THE National Research Council of Washington, U.S.A., is the American counterpart of the Department of Scientific and Industrial Research in this country. It was organised in 1916 at the request of the president of the National Academy of Sciences, under its Congressional charter, as a measure of national preparedness; and President Wilson in 1918 , by executive order, requested the National Academy of Sciences to perpetuate the National Research Council, and assigned to it definite duties. We have before us a number of publications issued by the National Research Council. It is explained that the Proceedings of the National Academy of Sciences has been designated as the official organ of the National Research Council for the publication of accounts of research, committee and other reports, and minutes. But the Council publishes also at irregular intervals the Bulletin of the National Research Council for the presentation of contributions other than proceedings; and it issues from time to time, under the general title of "The Reprint and Circular Series of the National Research Council," papers published or printed by or for the Council and relating to matters in its designated field of action. Some of these papers have already appeared in scientific and technical journals.

The first four numbers of the Bulletin already issued deal with "The National Importance of Scientific and Industrial Research," "Research Laboratories in Industrial Establishments of the U.S.A.," "Periodical Bibliographies and Abstracts for the Scientific and Technological Journals of the World," and "North American Forest Research." Of the Reprint and Circular Series the first nine numbers cover a wide and diversified area, including reports of NO. 2682 , vOL. IO7] the Patent and Psychology Committees of the National Research Council; papers on problems of refractory materials, solar and terrestrial radiation, sidereal astronomy, and industrial research; and, finally, a " reading list on scientific and industrial research and the service of the chemist to industry."

Some of these publications can, perhaps, better be dealt with by way of separate review, but it may be useful here to direct attention to certain points raised that bear on the general question of scientific research, particularly in its application to industry. The "reading list" referred to above shows the extent of this field, for it contains something like Iroo references to books, pamphlets, and articles under the popular classification of ( $\mathrm{I}$ ) scientific research and (2) industrial research, and the flood continues. As one writer says:- "Newspapers, magazines, and periodicals are continually publishing articles on industrial research; vast numbers of people are talking, more or less knowingly, about it; and industries and Governmental Departments, which up to a few years ago had hardly heard of industrial research, are em. barking or endeavouring to embark upon the most elaborate research projects."

In all this restless stirring amongst the dry bones there is a great need to keep constantly in mind a few paramount and fundamental principles. The first is that the main instrument of research is man, and not machinery, instruments, or buildings. $\mathrm{Mr}$. Frank B. Jewett, chief engineer of the Western Electric Co., in a paper on "Industrial Research," well says : "The matter of an adequate supply of properly equipped and trained investigators and directors of research is absolutely vital to the growth of industrial research, and $I$ am as sure as one can be of anything 
in the worid that all of our visions of the benefits to be derived from a large expansion of industrial research will come to naught if we fail to realise or neglect the fact that in the last analysis we are dependent absolutely upon the mental productivity of men, and men alone, and that we must, in consequence, provide adequately for a continuous supply of well-trained workers." It is, and must be, the function of the universities and higher educational institutions to pour out the steady stream of wellequipped and trained investigators that is the first and vital need of the industrial research movement.

Another essential condition for the successful development of industrial research is that there must be concurrently a corresponding growth and development in the domain of fundamental scientific research -what is, perhaps somewhat loosely, called "pure science" - for from the fountains of pure science come the waters that freshen and replenish the streams of applied research. It is worthy of note, and should be reassuring even to those who look with distrust on the more recent developments of industrial research, that in the various papers published by the National Research Council dealing with the application of science to industry there is abundant testimony from men whose main interests are industrial to the truth of this principle. Mr. I. J. Cartv, vicepresident of the American Telephone and Telegraph Co., for example, in an address on "Science and the Industries," says: "The pure scientists are the advance guard of civilisation. Bv their discoveries thev furnish to the engineer and industrial chemist and other applied scientists the raw material to be elaborated into manifold agencies for the amelioration of the rondition of mankind. Unless the work of the pure scientist is continued and pushed forward with ever-increasing energv, the achievements of the industrial scientist will diminish and degenerate." It is, again, to the universities mainly, if not almost wholly, that we must look for this fundamental, purely scientific research. The publications under review perform not the least useful of their functions in emphasising the basic importance of the universities in all schemes for the national development of industrial research.

The last point with which in our limited space we can deal is the fundamental question of the organisa. tion of research. Dr. James Rowland Angell, in an address on "The Development of Research in the United States," says: "Scientific men have as yet only achieved the most elementary beginnings of the organisation of scientific interests. Indeed, it has been something of a fetish among scientists that we must rely upon individual inspiration and initiative, and that the individual worker must be safeguarded in every possible way from the corroding influence of administrative organisation." This complaint is not baseless. There are still people who regard the mere suggestion of organising research as a profanation of genius not less desecrating than a proposal to have poetry written by committees; and yet scientific principles and methods are no more out of place in the organisation of research than they are in research itself. It may be long before we reach common agreement as to the main plan, but the science of the organisation of research is as worthy a study asshall we say?-the science of education or of economics. Dr. Angell, in the address referred to above, observes: "As a matter of fact, large areas of the most needed research lie in territory where properly trained men of talent, given proper conditions of work, may produce constantly and in increasing measure results of the utmost consequence. But one of the conditions of maximal efficiency is that they shall work inside the framework of a general pro. gramme in which there is intelligent co-operation in the allocation of the field and in the constant communication of results arhieved. Such distribution of responsibility and effort is entirely consonant with the fullest actual initiative which any scientist can desire."

The publications of the National Research Council are a solid contribution to the elucidation of many problems in this new and promising field of national development.

\section{Psychotherapy and War Experience.}

NABILITY to see the wood for the trees is not uncommon in writers on most scientific subjects, but the characteristic of many medical exponents of psychotherapy seems rather that to them the wood is invisible because of their proximity to one very large and important tree. Dr. William A. Brend, who contributes a notable article entitled "Psychotherapy and War Experience" to the January issue of the Edin burgh Review, is emphatically not one of these. His essay attracts one, apart from the obvious interest and importance of its subject. on account of the balance, the perspective, the background, and the sympathetic appreciation of delicate nuances which the picture displays. It is a lucid and judicious account of the substance of eight publications-not all of them recent-by Freud, Ferenczi, Ernest Jones, Lay, and McCurdy; but it is much more than this, for it gives the general reader some idea of the changes which the psycho-analytic movement has brought about in the outlook of modern psychotherapy. Yet Dr. Brend obviously holds no brief for this school of thought alone. He describes, too, the parts which suggestion (including hypnotism), persuasion, re-education, and modified psycho-analysis have played in alleviating the mental sufferings caused by the war, the unwisdom of encouraging the patient merely to "distract his mind" whether by play or by work, the inadvisability of allowing important lost memories to remain lost, the uses of hypnosis in No. 2682 , VOL. IO7] recovering repressed experiences, the indispensability of thorough-going psycho-analysis in some cases and its undesirability in others.

"Some knowledge of the principles of the new psychology is desirable for everyone, but that is not to say that a person of normal mentality should, without good reason, allow all his natural repressions to be brought to the surface by anyone who claims to be an analyst."

It is hoped that many will read of the extensive provision of psychotherapy made by the Army since I916, and at present by the Ministry of Pensions under Sir Lisle Webb, and that they will then inquire what is being done for the civilian. The answer is :

"As far as the ordinary civilian population is concerned, very few facilities for this treatment are available for those who are unable to pay the fees of consultants. One or two clinics have been started on a small scale, but it is now recognised that to cover the ground adequately very large provision of this nature will require to be made, and it is to be hoped that such clinics will eventually be established under the Ministry of Health."

Those of us who almost daily have sadly to tell sufferers that "very few facilities for this treatment are available for those who are unable to pay the fees of consultants" very earnestly share the hope of Dr. Brend. 